\title{
INFLUÊNCIA DO TIPO E DA QUANTIDADE DE RESÍDUOS VEGETAIS NA EFICÁCIA DE HERBICIDAS APLICADOS EM PRÉ-EMERGÊNCIA NA CULTURA DA SOJA $\left({ }^{1}\right)$
}

\author{
NÚBIA MARIA CORREIA $\left({ }^{2 *}\right)$; JULIO CEZAR DURIGAN $\left({ }^{2}\right)$; URUBATAN PALHARES KLINK $\left({ }^{3}\right)$
}

\begin{abstract}
RESUMO
Com o objetivo de avaliar, em condições de campo e na região originalmente sob cerrado, os efeitos de resíduos vegetais [sorgo de cobertura (híbrido Cober Exp), milheto forrageiro (var. BN2), capimpé-de-galinha (Eleusine coracana) e capim-braquiária (Brachiaria brizantha)] e duas quantidades de palha (3,0 e 5,5 $\mathrm{t} \mathrm{ha}^{-1}$, no primeiro ano do estudo, e 3,5 e 5,8 $\mathrm{t} \mathrm{ha}^{-1}$, no segundo) na eficácia de herbicidas residuais (diclosulam e imazaquin) aplicados em pré-emergência na cultura da soja, foi desenvolvido experimento, no ano agrícola 2003/2004 e repetido em 2004/2005, na fazenda Três Marcos, em Uberlândia (MG). Os herbicidas diclosulam e imazaquin não tiveram a eficácia afetada pela presença de palha na superfície do solo, independentemente da quantidade. Associados às coberturas, obteve-se melhor controle. No primeiro ano, após a instalação da cultura da soja, plantas de Eleusine coracana tornaram-se as principais infestantes na parcela de capim-pé-de-galinha.
\end{abstract}

Palavras-chave: cerrado, cobertura morta, controle químico, manejo integrado, plantas daninhas, sistema de semeadura direta.

\section{ABSTRACT \\ INFLUENCE OF THE TYPE AND AMOUNT OF CROP RESIDUES IN EFFICIENCY OF HERBICIDES APPLIED PRE-EMERGENCE IN SOYBEAN}

This work was conducted in the agricultural years 2003/04 and 2004/05, at the farm 'Três Marcos', Uberlândia, MG - Brazil to evaluate the effect of crop residues [coverage sorghum (hybrid Cober Exp), forage millet (var. BN2), finger millet (Eleusine coracana) and St. Lucia Grass (Brachiaria brizantha)] and two amounts of straw (3.0 and $5.5 \mathrm{t} \mathrm{ha}^{-1}$ in the first year and 3.5 and $5.8 \mathrm{t} \mathrm{ha}^{-1}$, in the second year) in efficiency of herbicides (diclosulam and uimazaquin) applied pre-emergence in soybean, 'Cerrado' conditions. The efficiency of herbicides diclosulam and imazaquin was not affected by the straw at any amount. Associated to the straw coverage, it had best weed control. In the first year, after the soybean field was installed, Eleusine coracana became the major weed species in the finger millet plot.

Key words: cerrado, mulch, chemical control, integrated management, weed, no-tillage system.

( $\left.{ }^{1}\right)$ Recebido para publicação em 23 de novembro de 2005 e aceito em 21 de novembro de 2006.

$\left({ }^{2}\right)$ Engenheiro Agrônomo, Doutor, Professor, Departamento de Fitossanidade. Universidade Estadual Paulista (UNESP). Campus de Jaboticabal, SP. Via de Acesso Prof. Paulo Donato Castellane, s/n. CEP: 14.884-900. Jaboticabal, SP, Brasil. Email: correianm@fcav.unesp.br*Autora correspondente; jcdurigan@fcav.unesp.br

$\left({ }^{3}\right)$ Monsanto do Brasil Ltda., Uberlândia (MG). E-mail: urubatan.p.klink@monsanto.com 


\section{INTRODUÇÃO}

A principal característica do sistema de semeadura direta é o não-revolvimento do solo. Em conseqüência, os resíduos das culturas anteriores e das plantas daninhas ficam sobre o terreno, formando o que se designa cobertura morta. São inúmeros os aspectos positivos atribuídos à permanência de uma cobertura, viva ou morta, sobre o solo, como proteção do solo e regeneração da sua fertilidade, aumento da infiltração de água no solo, redução da amplitude térmica do solo, criação de ambiente propício para atividade biológica, melhoria da estrutura do solo, substanciais efeitos na flora infestante, dentre outros.

No entanto, o tipo e a quantidade de resíduos vegetais mantidos sobre o solo podem comprometer a capacidade de um herbicida residual em atingi-lo, devido a sua retenção do pela palha, não permitindo o contato com o solo. Dependendo das características físico-químicas dos herbicidas, como solubilidade, volatilidade e polaridade, a palha terá maior ou menor influência na sua eficácia (Rodrigues, 1993). A quantidade e época das chuvas que ocorrem após a aplicação, além de mudanças na constituição química dos materiais vegetais em decomposição, também podem exercer grande influência na retenção dos herbicidas pela palha.

A associação de atrazine mais metolachlor contribuiu significativamente para o controle de plantas daninhas de "folhas largas", independentemente do nível de palha de milho $(0,3$, 6, 9 e $12 \mathrm{t} \mathrm{ha}^{-1}$ ) e da época de avaliação (26 e 41 dias após a aplicação), em virtude da ação do atrazine. No entanto, houve menor efeito, em especial do metolachlor, sobre a população de gramíneas, o que pode ser atribuído, possivelmente, a sua retenção pela cobertura morta, impedindo a ação sobre as plantas daninhas (Oliveira et al., 2001).

O tipo de cobertura (vegetação espontânea, Vicia villosa e Triticum aestivum) influenciou na interceptação de herbicida fluometuron e na sua lixiviação até o solo, possivelmente por diferenças na quantidade de biomassa produzida e acumulada sobre o solo e na constituição química dos resíduos (GASTON et al., 2001).

Cerca de $3,5 \mathrm{t} \mathrm{ha} \mathrm{a}^{-1}$ de palha de trigo foram suficientes para interceptar e reter $5 \%$ do herbicida metribuzin aplicado sobre os resíduos mantidos eretos e $80 \%$, quando os resíduos encontravam-se esparramados sobre o solo, mesmo após irrigação de $20 \mathrm{~mm}$ (DAO, 1995). Pelos resultados verifica-se que a área de cobertura dos resíduos vegetais no solo também assume grande importância em estudos dessa natureza, talvez até mais que a quantidade de palha remanescente sobre o solo. Neste mesmo trabalho, após chuva de $25 \mathrm{~mm}$ ocorrida um dia após a irrigação, apenas $12 \%$ e $20 \%$ do metribuzin permaneciam retidos na palha de trigo mantida ereta ou esparramada sobre o solo respectivamente.

Os benefícios proporcionados pelo sistema de semeadura direta são incontestáveis, ou ao solo, aos mananciais de água ou ao sistema produtivo como um todo. Contudo, algumas dúvidas ainda se fazem pertinentes e precisam ser esclarecidas, como o efeito da palha produzida por espécies promissoras para a formação de massa no cerrado, na atuação de controle dos herbicidas diclosulam e imazaquin, os mais utilizados em pré-emergência na cultura da soja, no preparo convencional do solo, naquela região. Com a mudança do sistema de cultivo, é necessário constatar se a eficácia desses herbicidas não é comprometida, diante da possível retenção deles pela palha mantida na superfície do solo.

O objetivo do presente trabalho foi avaliar, em condições de campo e na região originalmente sob cerrado, os efeitos dos tipos e das quantidades de resíduos vegetais, produzidos "in locu", na eficácia de herbicidas residuais aplicados em pré-emergência na cultura da soja no sistema de semeadura direta.

\section{MATERIAL E MÉTODOS}

O experimento foi desenvolvido durante o período de fevereiro de 2003 a março de 2004, e repetido de março de 2004 a março de 2005, na mesma área experimental, na Fazenda Três Marcos, localizada em Uberlândia (MG). A altitude do local é de, aproximadamente, 872 metros, a latitude de $18^{\circ} 55^{\prime} \mathrm{S}$ e a longitude de $48^{\circ} 17^{\prime} \mathrm{W}$. Segundo a classificação de Köeppen, o clima da região é do tipo Aw. O solo da área experimental é representativo da região, classificado como Latossolo VermelhoAmarelo distroférrico, textura argilosa, originalmente sob vegetação de cerrado, submetido ao sistema de semeadura direta há quatro anos, com as culturas milho/sorgo no inverno e soja/crotalária no verão.

O delineamento experimental utilizado foi o de blocos ao acaso, em esquema de parcelas subsubdivididas, com quatro repetições. Foram mantidos quatro tipos de cobertura nas parcelas: sorgo de cobertura (Sorghum bicolor x S. sudanensis 'Cober Exp'), milheto forrageiro (Pennisetum americanum 'BN2'), capim-pé-de-galinha (Eleusine coracana) e capimbraquiária (Brachiaria brizantha). Duas quantidades de palha nas subparcelas: 3,0 e 5,5 $\mathrm{t} \mathrm{ha}^{-1}$, no ano primeiro ano, e 3,5 e 5,8 $\mathrm{t} \mathrm{ha}^{-1}$, no segundo. Nas sub- 
subparcelas foram aplicados dois herbicidas: o diclosulam $\left(35 \mathrm{~g} \mathrm{ha}^{-1}\right)$ e o imazaquin $\left(140 \mathrm{~g} \mathrm{ha}^{-1}\right)$. Além disso, foram estabelecidas quatro testemunhas como tratamentos adicionais, sem restos culturais. Em duas delas foram aplicados os herbicidas, o diclosulam em uma, e o imazaquin em outra. As outras duas testemunhas não foram tratadas com os herbicidas, sendo uma capinada até o fechamento da cultura, e a outra mantida infestada.

As culturas de cobertura foram instaladas na última semana de fevereiro de 2003 e na primeira de março de 2004. Para a obtenção das duas quantidades de palha, variaram-se as densidades de semeadura de milheto forrageiro (10 e $\left.15 \mathrm{~kg} \mathrm{ha}^{-1}\right)$, capim-pé-de-galinha

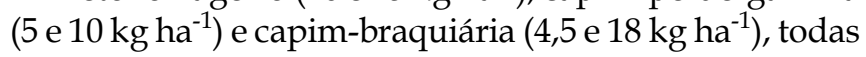
semeadas a lanço. $\mathrm{O}$ sorgo de cobertura foi semeado na quantidade de $15 \mathrm{~kg} \mathrm{ha}^{-1}$, a lanço e em linha.

As sementes produzidas foram, juntamente com os outros resíduos vegetais, depositadas ao solo, com auxílio de uma roçadora, em julho de 2003. No ano seguinte, as plantas não foram cortadas, atingindo o solo apenas com a ação dos ventos ou de máquinas agrícolas, no momento da "dessecação" e da semeadura da soja.

$\mathrm{Na}$ segunda quinzena de outubro, fez-se a dessecação da área experimental, utilizando-se, no primeiro ano, o herbicida glyphosate na dosagem de 1,44 $\mathrm{kg} \mathrm{ha}^{-1}$ de equivalente ácido e, no segundo, a mistura em tanque de $1,44 \mathrm{~kg} \mathrm{ha}^{-1}$ de equivalente ácido de glyphosate e $80 \mathrm{~g} \mathrm{ha}^{-1}$ de carfentrazone-ethyl, em virtude da ocorrência de Commelina benghalensis. Após sete dias, as parcelas com capim-braquiária foram novamente tratadas com glyphosate na mesma dosagem.

Após a formação da cobertura morta, foi realizada uma amostragem em cada subparcela para quantificação do equivalente em palha por hectare. Dentro da área útil de cada subparcela foram coletados os resíduos vegetais, na área de $0,25 \mathrm{~m}^{2}$, em quatro pontos escolhidos aleatoriamente. A palha coletada foi cuidadosamente peneirada e limpa com o auxílio de um pincel, para se retirar as partículas de solo aderidas a ela. As amostras foram acondicionadas em sacos de papel e encaminhadas ao laboratório para pesagem. Pela análise estatística, pelo teste de Tukey a $5 \%$ de probabilidade, constatou-se que dentro de cada nível de palha não havia diferença significativa entre os tipos de cobertura, com os valores de 3,0 e $5,5 \mathrm{t} \mathrm{ha}^{-1}$, para menor e maior nível, no ano de 2003/ 04 , e de 3,5 e $5,8 \mathrm{t} \mathrm{ha}^{-1}$, no ano seguinte.

Devido à ausência de chuvas, não foram verificados fluxos de emergência de plantas daninhas, no intervalo entre a primeira e a segunda dessecação realizada na parcela de capim-braquiária.
O mesmo persistiu até a aplicação dos herbicidas residuais, quinze dias após a primeira dessecação.

Com base em análises de solo (Tabela 1), coletado de 0 a $20 \mathrm{~cm}$ de profundidade para cada tratamento, e na necessidade nutricional da soja, fezse a recomendação de adubação, igual para todas as parcelas. Foram aplicados $300 \mathrm{~kg} \mathrm{ha}^{-1}$ do formulado 02-20-20 no sulco de semeadura, no primeiro ano, e 400 $\mathrm{kg} \mathrm{ha}^{-1}$ do mesmo formulado, no ano de 2004/2005. Além disso, as sementes foram inoculadas com $3 \mathrm{~mL}$ de Urulec- $\mathrm{L} \mathrm{kg}^{-1}$ de sementes, no ano de 2003/04, e com $2 \mathrm{~g}$ de Biomax $\mathrm{kg}^{-1}$ de sementes, no ano seguinte.

A soja foi semeada em sistema de semeadura direta, na última semana de outubro de 2003 e na primeira de novembro em 2004, a uma profundidade de $5 \mathrm{~cm}$, com $0,5 \mathrm{~m}$ de distância entre as linhas e 23 sementes por metro, em 2003/2004, e 26 sementes, em 2004/2005, utilizando a cultivar M-SOY 6101. Foi usada a semeadora Semeato Par 2800, de seis linhas, no primeiro ano, e semeadora Semeato Shm, de quatro linhas, no ano seguinte.

As parcelas (tipos de cobertura) estavam com $6 \mathrm{~m}$ de largura e $10 \mathrm{~m}$ de comprimento. Dentro de cada parcela foram demarcadas as subparcelas (quantidades de palha), com $3 \mathrm{~m}$ de largura e $10 \mathrm{~m}$ de comprimento, onde foram delimitadas as subsubparcelas (herbicidas residuais), constituídas por seis linhas de soja com $5 \mathrm{~m}$ de comprimento, com 4 linhas centrais de $4 \mathrm{~m}$ de comprimento como área útil, totalizando $8 \mathrm{~m}^{2}$.

Os herbicidas diclosulam e imazaquin foram aplicados no dia seguinte à semeadura da soja, em pré-emergência, com pulverizador costal, à pressão constante (mantida pelo $\mathrm{CO}_{2}$ comprimido) de $2,24 \mathrm{kgf}$ $\mathrm{cm}^{-2}$, munido de barra com seis bicos de jato plano "leque" 110.02, espaçados de $0,5 \mathrm{~m}$, com consumo de calda equivalente a $200 \mathrm{~L} \mathrm{ha}^{-1}$. Os valores das temperaturas do ar e do solo, da umidade relativa do ar e as condições de vento, no momento das aplicações, estão relacionados na tabela 2.

Aos 14, 28, 42 e 56 dias após a aplicação dos herbicidas (DAA), no primeiro ano, e aos 11, 20, $32 \mathrm{e}$ 45 DAA, no segundo, foram realizadas avaliações visuais de controle das plantas daninhas, em porcentagem. Para cada unidade experimental foi atribuída a nota média de dois avaliadores.

Aos 56 DAA, em 2003/2004, e 45 DAA, no ano de 2004/2005, coletou-se a parte aérea das plantas daninhas, em área de $0,25 \mathrm{~m}^{2}$, escolhida aleatoriamente dentro da área útil da unidade experimental, a fim de se determinar a matéria seca. O material foi acondicionado em sacos de papel e levado à estufa com circulação forçada de ar, mantido a $65{ }^{\circ} \mathrm{C}$, até atingir massa constante, quando foi pesado. 
Tabela 1. Resultados das análises de solo realizadas antes da semeadura da soja, em duas épocas de coleta. Uberlândia - MG, 2003/04 e 2004/2005

\begin{tabular}{|c|c|c|c|c|c|c|c|c|c|c|}
\hline \multirow{2}{*}{ Coleta } & \multicolumn{2}{|c|}{ Tratamentos } & \multirow{2}{*}{$\begin{array}{c}\text { pH água } \\
(1: 2,5)\end{array}$} & \multirow{2}{*}{$\mathrm{P}$} & \multirow{2}{*}{$\mathrm{K}$} & \multirow{2}{*}{$\mathrm{Ca}$} & \multirow{2}{*}{$\mathrm{Mg}$} & \multirow{2}{*}{$\mathrm{Al}$} & \multirow{2}{*}{$\mathrm{V}$} & \multirow{2}{*}{$\mathrm{MO}$} \\
\hline & Tipos de cobertura & Nivel & & & & & & & & \\
\hline & & t.ha ${ }^{-1}$ & & $\mathrm{mg} \mathrm{dm}^{-3}$ & 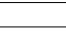 & $-\mathrm{mr}$ & $\mathrm{m}^{-3}$ & & $\%$ & $\mathrm{~g} \mathrm{dm}^{-3}$ \\
\hline \multirow{9}{*}{ Out/2003 } & \multirow[t]{2}{*}{ Sorgo } & 5,5 & 5,9 & 11,3 & 2,8 & 22 & 9 & 0 & 58 & 24 \\
\hline & & 3,0 & 5,6 & 16,3 & 2,5 & 20 & 9 & 0 & 51 & 26 \\
\hline & \multirow[t]{2}{*}{ Milheto forrageiro } & 5,5 & 5,7 & 16,0 & 3,6 & 23 & 9 & 0 & 58 & 26 \\
\hline & & 3,0 & 5,7 & 16,8 & 4,2 & 20 & 8 & 0 & 53 & 26 \\
\hline & \multirow[t]{2}{*}{ Capim-pé-de-galinha } & 5,5 & 5,4 & 16,1 & 3,3 & 20 & 8 & 0 & 47 & 24 \\
\hline & & 3,0 & 5,3 & 26,2 & 2,9 & 18 & 7 & 0 & 40 & 24 \\
\hline & \multirow[t]{2}{*}{ Capim-braquiária } & 5,5 & 5,7 & 22,5 & 4,6 & 21 & 8 & 0 & 50 & 29 \\
\hline & & 3,0 & 5,8 & 77,2 & 5,0 & 24 & 10 & 0 & 53 & 29 \\
\hline & Testemunha & - & 5,3 & 68,3 & 3,0 & 22 & 8 & 0 & 44 & 25 \\
\hline \multirow{9}{*}{ Out/2004 } & \multirow[t]{2}{*}{ Sorgo } & 5,8 & 5,5 & 15,4 & 2,3 & 21 & 7 & 0 & 46 & 24 \\
\hline & & 3,5 & 5,5 & 15,3 & 3,7 & 22 & 7 & 0 & 50 & 24 \\
\hline & \multirow[t]{2}{*}{ Milheto forrageiro } & 5,8 & 5,4 & 72,5 & 4,0 & 17 & 5 & 0 & 41 & 21 \\
\hline & & 3,5 & 5,9 & 21,4 & 3,2 & 20 & 7 & 0 & 52 & 19 \\
\hline & \multirow[t]{2}{*}{ Capim-pé-de-galinha } & 5,8 & 5,3 & 29,2 & 3,6 & 14 & 4 & 0 & 33 & 22 \\
\hline & & 3,5 & 5,4 & 20,2 & 4,1 & 18 & 6 & 0 & 45 & 22 \\
\hline & \multirow[t]{2}{*}{ Capim-braquiária } & 5,8 & 5,9 & 17,4 & 3,1 & 25 & 7 & 0 & 58 & 22 \\
\hline & & 3,5 & 5,8 & 14,7 & 3,2 & 26 & 8 & 0 & 57 & 24 \\
\hline & Testemunha & - & 5,7 & 26,9 & 3,2 & 24 & 8 & 0 & 53 & 24 \\
\hline
\end{tabular}

Tabela 2. Temperaturas do ar e do solo, umidade relativa do ar e condições de vento, no momento das aplicações dos herbicidas. Uberlândia (MG), 2003/2004 e 2004/2005

\begin{tabular}{|c|c|c|c|c|}
\hline \multirow{2}{*}{ Ano agrícola } & \multicolumn{2}{|c|}{ Temperatura } & \multirow{2}{*}{ Umidade relativa do ar } & \multirow{2}{*}{ Condições de vento } \\
\hline & Ar & Solo & & \\
\hline & 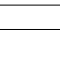 & 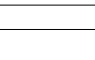 & $\%$ & \\
\hline $2003 / 2004$ & 29 & 26,4 & 51 & Brisa suave \\
\hline $2004 / 2005$ & 27 & 25,2 & 59 & Brisa suave \\
\hline
\end{tabular}

Os resultados obtidos foram submetidos ao teste $\mathrm{F}$ da análise de variância. Os efeitos dos tipos de cobertura, níveis e herbicidas, quando significativos, foram comparados pelo teste de Tukey a $5 \%$ de probabilidade. Por contrastes, fez-se a comparação das testemunhas sem cobertura e os tratamentos com palha.

\section{RESULTADOS E DISCUSSÃO}

No primeiro ano, a interação entre tipos de cobertura, níveis e herbicidas foi significativa para a porcentagem de controle de plantas daninhas aos 42 e 56 dias após a aplicação (DAA) dos herbicidas e para matéria seca de plantas, indicando dependência entre os fatores. Para melhor interpretação e compreensão dos resultados optou-se pelo desdobramento dos herbicidas dentro das combinações entre níveis e coberturas. As interações entre tipos e níveis foram significativas para controle aos 14 DAA e, entre tipos e herbicidas, níveis e herbicidas e tipos e níveis para controle aos 28 DAA.

Aos 14 DAA, os herbicidas diclosulam e imazaquin resultaram em controle similar das plantas daninhas, até então as diferenças observadas foram causadas pelo tipo e quantidade de cobertura na superfície do solo. Como pode ser observado na tabela 3, nos dois níveis estudados, aos 14 e 28 DAA, houve controle ineficaz das plantas daninhas sob a palha de capim-pé-de-galinha, diferindo significativamente das demais.

Através da comparação por contrastes, verificou-se, aos $14 \mathrm{DAA}$, que as testemunhas tratadas com diclosulam e imazaquin não diferiram entre si e, obtiveram controle semelhante ao observado no menor nível de palha de capim-pé-de-galinha. Contudo, obteve-se melhor controle das plantas daninhas quando se fez a associação dos herbicidas às demais coberturas estudadas. 
Tabela 3. Percentagem de controle das plantas daninhas, aos 14 e 28 dias após a aplicação (DAA), em pré-emergência, dos herbicidas diclosulam e imazaquin sobre quatro tipos de cobertura e dois níveis de palha, além das testemunhas (sem palha). Uberlândia (MG), 2003/2004

\begin{tabular}{|c|c|c|c|c|}
\hline \multirow{3}{*}{ Tipos de cobertura } & \multicolumn{4}{|c|}{ Níveis de palha $\left(\mathrm{t} \mathrm{ha}^{-1}\right)$} \\
\hline & 3,0 & 5,5 & 3,0 & 5,5 \\
\hline & \multicolumn{2}{|c|}{$14 \mathrm{DAA}$} & \multicolumn{2}{|c|}{$28 \mathrm{DAA}$} \\
\hline Sorgo & 83,13 a B & 95,88 a $\mathrm{A}$ & 74,00 a B & 87,13 a $\mathrm{A}$ \\
\hline Milheto forrageiro & 87,25 a A & 90,38 a A & 73,75 a B & 87,75 a $\mathrm{A}$ \\
\hline Capim-pé-de-galinha & $55,00 \mathrm{~b} \mathrm{~A}$ & $37,50 \mathrm{~b} \mathrm{~B}$ & $31,25 \mathrm{~b} \mathrm{~A}$ & $21,25 \mathrm{~b} \mathrm{~B}$ \\
\hline Capim-braquiária & 85,75 a B & 92,25 a A & 72,75 a B & 86,50 a $\mathrm{A}$ \\
\hline DMS (na linha) & \multicolumn{2}{|c|}{4,32} & \multicolumn{2}{|c|}{5,31} \\
\hline DMS (na coluna) & \multicolumn{2}{|c|}{7,18} & \multicolumn{2}{|c|}{8,22} \\
\hline Test. s/ palha tratada c/ diclosulam & \multicolumn{2}{|c|}{47,50} & \multicolumn{2}{|c|}{61,25} \\
\hline Test. s/ palha tratada c/ imazaquin & \multicolumn{2}{|c|}{46,25} & \multicolumn{2}{|c|}{40,00} \\
\hline Test. s/ palha mantida infestada & \multicolumn{2}{|c|}{0,00} & \multicolumn{2}{|c|}{0,00} \\
\hline
\end{tabular}

Com base no teste de Tukey a 5\% de probabilidade, médias seguidas de letra minúscula, nas colunas, comparam tipos de cobertura dentro de cada nível de palha e, letras maiúsculas, nas linhas, comparam os dois níveis para cada cobertura.

Como pode ser constatado na tabela 4 , quanto aos efeitos dos herbicidas para cada cobertura, obtevese, aos 28 DAA, menor porcentagem de controle das plantas daninhas sob palha de capim-pé-de-galinha, para ambos os herbicidas. Para todas as coberturas, o controle foi mais eficaz quando se aplicou o diclosulam, com exceção de milheto forrageiro, onde não houve diferença entre os herbicidas. Por contrastes, observou-se que a testemunha tratada com diclosulam diferiu significativamente da tratada com imazaquin. Quando os herbicidas foram aplicados sobre as palhas de sorgo, milheto forrageiro e capimbraquiária, houve melhor controle das plantas daninhas. Para o capim-pé-de-galinha, nos seus dois níveis de palha, o controle foi ineficaz, com valor inferior ao constatado nas testemunhas sem palha e tratadas com os herbicidas.

Não foi observada diferença significativa entre os níveis de palha, quando aplicado o diclosulam, ao contrário do imazaquin que resultou em melhor controle no maior nível (dados não mostrados). Por contrastes, verificou-se que o imazaquin associado ao menor nível de palha não diferiu da sua testemunha sem palha. Todavia, com a adição de $5,5 \mathrm{t} \mathrm{ha}^{-1}$ de palha sobre o solo, obteve-se melhor controle que o da sua testemunha sem palha. A testemunha tratada com diclosulam diferiu dos dois níveis de cobertura que o receberam, com maior média para estes.

O baixo controle verificado nos tratamentos com palha de capim-pé-de-galinha não pode ser atribuído à retenção dos herbicidas pela palha e, sim, à alta infestação do próprio capim-pé-de-galinha na cultura da soja. As plantas dessa espécie produziram sementes, as quais foram depositadas ao solo com o manejo da cultura. Com o início do período chuvoso, houve um fluxo de emergência e suas plântulas foram eliminadas com a dessecação. No entanto, novos fluxos de emergência foram constatados após a semeadura da soja, infestando a cultura. O herbicida imazaquin não controla nem suprime essa gramínea e, apesar do efeito supressor do diclosulam, este não foi suficiente para o referido controle. Desta forma, ela tornou-se a planta daninha mais problemática sobre sua própria cobertura.

Tabela 4. Porcentagem de controle das plantas daninhas, aos 28 dias após a aplicação (DAA), em pré-emergência, dos herbicidas diclosulam e imazaquin sobre quatro tipos de cobertura, além das testemunhas (sem palha). Uberlândia (MG), 2003/2004

\begin{tabular}{lcc}
\hline Tipos de cobertura & Diclosulam & Imazaquin \\
\hline Sorgo & 84,38 a A & 76,75 a B \\
Milheto forrageiro & 83,38 a A & 78,13 a A \\
Capim-pé-de-galinha & 47,50 b A & 5,00 b B \\
Capim-braquiária & 85,63 a A & 73,63 a B \\
\hline DMS (na linha) & \multicolumn{3}{c}{6,87} \\
DMS (na coluna) & 9,07 \\
Testemunha sem palha & \multicolumn{2}{c}{0,00} \\
e mantida infestada & & \\
$\begin{array}{l}\text { Testemunha sem palha e } \\
\text { tratada com os herbicidas }\end{array}$ & 61,25 & 40,00 \\
\hline
\end{tabular}

Com base no teste de Tukey a $5 \%$ de probabilidade, médias seguidas de letra minúscula, nas colunas, comparam tipos de cobertura dentro de cada herbicida e, letras maiúsculas, nas linhas, comparam herbicidas para cada cobertura. 
Tabela 5. Percentagem de controle das plantas daninhas, aos 42 dias após a aplicação (DAA), em pré-emergência, dos herbicidas diclosulam e imazaquin, sobre quatro tipos de cobertura e dois níveis de palha, além das testemunhas (sem palha). Uberlândia (MG), 2003/2004

\begin{tabular}{|c|c|c|c|c|}
\hline \multirow{3}{*}{ Tipos de cobertura } & \multicolumn{4}{|c|}{ Níveis de palha $\left(\mathrm{t} \mathrm{ha}^{-1}\right)$} \\
\hline & 3,0 & 5,5 & 3,0 & 5,5 \\
\hline & \multicolumn{2}{|c|}{ Diclosulam } & \multicolumn{2}{|c|}{ Imazaquin } \\
\hline Sorgo & 79,50 a B & 86,50 a $A$ & 66,25 a B & 83,00 a $\mathrm{A}$ \\
\hline Milheto forrageiro & 79,75 a B & 87,75 a $\mathrm{A}$ & 63,75 a B & 83,00 a $\mathrm{A}$ \\
\hline Capim-pé-de-galinha & $11,25 \mathrm{~b} \mathrm{~A}$ & $16,25 \mathrm{~b} \mathrm{~A}$ & $1,25 \mathrm{~b} \mathrm{~A}$ & $0,00 \mathrm{~b} \mathrm{~A}$ \\
\hline Capim-braquiária & 80,75 a A & 83,00 a $\mathrm{A}$ & 63,25 a B & 77,50 a $\mathrm{A}$ \\
\hline DMS (na linha) & \multicolumn{2}{|c|}{6,95} & \multicolumn{2}{|c|}{7,17} \\
\hline DMS (na coluna) & \multicolumn{2}{|c|}{13,69} & \multicolumn{2}{|c|}{8,29} \\
\hline Test. s/ palha trat. c/ herb. $\left({ }^{1}\right)$ & \multicolumn{2}{|c|}{55,00} & \multicolumn{2}{|c|}{25,00} \\
\hline Test. s/ palha $\left({ }^{2}\right)$ & \multicolumn{2}{|c|}{0,00} & \multicolumn{2}{|c|}{0,00} \\
\hline
\end{tabular}

Com base no teste de Tukey a 5\% de probabilidade, médias seguidas de letra minúscula, nas colunas, comparam tipos de cobertura dentro de cada nível de palha e, letras maiúsculas, nas linhas, comparam os dois níveis para cada cobertura. ( $\left(^{1}\right)$ Testemunha sem palha e tratada com os herbicidas. ( $\left(^{2}\right)$ Testemunha sem palha e mantida infestada.

Tabela 6. Percentagem de controle das plantas daninhas, aos 56 dias após a aplicação (DAA), em pré-emergência, dos herbicidas diclosulam e imazaquin, sobre quatro tipos de cobertura e dois níveis de palha, além das testemunhas (sem palha).Uberlândia (MG), 2003/2004

\begin{tabular}{|c|c|c|c|c|}
\hline \multirow{3}{*}{ Tipos de cobertura } & \multicolumn{4}{|c|}{ Níveis de palha $\left(\mathrm{t} \mathrm{ha} \mathrm{a}^{-1}\right)$} \\
\hline & 3,0 & 5,5 & 3,0 & 5,5 \\
\hline & \multicolumn{2}{|c|}{ Diclosulam } & \multicolumn{2}{|c|}{ Imazaquin } \\
\hline Sorgo & 80,50 a $\mathrm{A}$ & 85,75 a $\mathrm{A}$ & 63,75 a B & 83,00 a $\mathrm{A}$ \\
\hline Milheto forrageiro & 79,75 a A & 86,00 a $\mathrm{A}$ & 61,25 a B & 77,50 a $\mathrm{A}$ \\
\hline Capim-pé-de-galinha & $7,50 \mathrm{~b} \mathrm{~B}$ & $15,00 \mathrm{~b} \mathrm{~A}$ & $0,00 \mathrm{~b} \mathrm{~A}$ & $0,00 \mathrm{~b} \mathrm{~A}$ \\
\hline Capim-braquiária & 81,25 a A & 82,75 a A & 56,75 a B & 77,50 a $\mathrm{A}$ \\
\hline DMS (na linha) & \multicolumn{2}{|c|}{7,30} & \multicolumn{2}{|c|}{7,15} \\
\hline DMS (na coluna) & \multicolumn{2}{|c|}{11,25} & \multicolumn{2}{|c|}{8,72} \\
\hline Test. s/ palha trat. c/ herb. $\left({ }^{1}\right)$ & \multicolumn{2}{|c|}{58,75} & \multicolumn{2}{|c|}{25,00} \\
\hline Test. s/ palha $\left({ }^{2}\right)$ & \multicolumn{2}{|c|}{0,00} & \multicolumn{2}{|c|}{0,00} \\
\hline
\end{tabular}

Com base no teste de Tukey a $5 \%$ de probabilidade, médias seguidas de letra minúscula, nas colunas, comparam tipos de cobertura dentro de cada nível de palha e, letras maiúsculas, nas linhas, comparam os dois níveis para cada cobertura. $\left({ }^{1}\right)$ Testemunha sem palha e tratada com os herbicidas. $\left({ }^{2}\right)$ Testemunha sem palha e mantida infestada.

Para as avaliações de controle realizadas aos 42 e 56 DAA e para matéria seca de plantas, os herbicidas diclosulam e imazaquin, novamente, resultaram em melhor controle quando aplicados sobre as coberturas de sorgo, milheto forrageiro e capimbraquiária, diferindo significativamente dos resultados obtidos na palha de capim-pé-de-galinha (Tabelas 5, 6 e 7). Para todos os tratamentos, independentemente do tipo e da quantidade de cobertura, o diclosulam resultam em de melhor potencial de controle que o imazaquin.

Pela análise por contrastes, constatou-se, aos 42 e 56 DAA, que as testemunhas sem palha e tratadas com diclosulam e imazaquin, tiveram, em média, melhor controle que o observado nos dois níveis de palha de capim-pé-de-galinha. Quanto à comparação das testemunhas com as palhas de sorgo, milheto forrageiro e capimbraquiária, os herbicidas resultaram em melhor controle nos tratamentos com palha.

As plantas daninhas sob o maior nível de palha de capim-pé-de-galinha, para os dois herbicidas, apresentaram maior matéria seca que as plantas das testemunhas tratadas com os herbicidas, as quais não diferiram do menor nível de palha de capim-pé-de-galinha e apresentaram maiores médias quando comparadas às demais coberturas estudadas. O acúmulo de massa das plantas daninhas na testemunha sem palha e mantida infestada foi maior que todos os outros tratamentos. 
Tabela 7. Acúmulo de matéria seca de plantas daninhas $\left(\mathrm{g} \mathrm{m}^{-2}\right)$, aos 56 dias após a aplicação (DAA), em pré-emergência, dos herbicidas diclosulam e imazaquin, sobre quatro tipos de cobertura e dois níveis de palha, além das testemunhas (sem palha). Uberlândia (MG), 2003/2004

\begin{tabular}{|c|c|c|c|c|}
\hline \multirow{3}{*}{ Tipos de cobertura } & \multicolumn{4}{|c|}{ Níveis de palha $\left(\mathrm{t} \mathrm{ha}^{-1}\right)$} \\
\hline & 3,0 & 5,5 & 3,0 & 5,5 \\
\hline & \multicolumn{2}{|c|}{ Diclosulam } & \multicolumn{2}{|c|}{ Imazaquin } \\
\hline Sorgo & 24,62 a A & 19,82 a $\mathrm{A}$ & $54,60 \mathrm{ab} \mathrm{A}$ & 26,24 a $A$ \\
\hline Milheto forrageiro & 17,85 a $\mathrm{A}$ & 6,66 a $\mathrm{A}$ & 39,88 a $\mathrm{A}$ & 17,96 а $\mathrm{A}$ \\
\hline Capim-pé-de-galinha & $53,14 \mathrm{~b} \mathrm{~A}$ & 80,75 b B & $102,13 \mathrm{~b} \mathrm{~A}$ & $147,29 \mathrm{~b} \mathrm{~B}$ \\
\hline Capim-braquiária & 14,52 a $\mathrm{A}$ & 10,03 a $\mathrm{A}$ & $61,35 \mathrm{ab} B$ & 15,36 a $\mathrm{A}$ \\
\hline DMS (na linha) & \multicolumn{2}{|c|}{15,86} & \multicolumn{2}{|c|}{38,48} \\
\hline DMS (na coluna) & \multicolumn{2}{|c|}{24,34} & \multicolumn{2}{|c|}{54,91} \\
\hline Test. s/ palha trat. c/ herb. $\left({ }^{1}\right)$ & \multicolumn{2}{|c|}{42,24} & \multicolumn{2}{|c|}{101,32} \\
\hline Test. s/ palha $\left({ }^{2}\right)$ & \multicolumn{2}{|c|}{227,21} & \multicolumn{2}{|c|}{227,21} \\
\hline
\end{tabular}

Com base no teste de Tukey a 5\% de probabilidade, médias seguidas de letra minúscula, nas colunas, comparam tipos de cobertura dentro de cada nível de palha e, letras maiúsculas, as linhas, comparam os dois níveis para cada cobertura. (1) Testemunha sem palha e tratada com os herbicidas. (') Testemunha sem palha e mantida infestada.

O controle ineficaz das plantas daninhas nas testemunhas sem palha e tratadas com diclosulam e imazaquin pode ser justificado pela diversidade de espécies presentes na comunidade infestante da área experimental, composta principalmente por Bidens pilosa, Acanthospemum hispidum, Amaranthus spinosus, A. retroflexus, A. hybridus, Nicandra physaloides, Commelina benghalensis, Cenchrus echinatus e Digitaria horizontalis.

Os resultados do segundo ano (ano agrícola 2004/2005) comprovaram que, independentemente do tipo e da quantidade, os herbicidas diclosulam e imazaquin não ficaram retidos aos resíduos vegetais, ou pelo menos não tiveram o potencial de controle afetado, havendo resultados bastante satisfatórios quando associados às coberturas. Neste ano, a eficácia dos herbicidas associados à palha de capim-pé-degalinha não foi prejudicada. Como não ocorreram fluxos expressivos de emergência de Eleusine coracana, após a semeadura da soja, esta espécie não se tornou problemática na sua própria parcela.

Através da análise de variância, verificou-se que a interação entre tipos de cobertura, níveis e herbicidas foi significativa apenas para matéria seca de plantas, indicando comportamento diferenciado e dependente entre os fatores para esta característica. As interações entre tipos e herbicidas e entre níveis e herbicidas foram significativas para controle aos 11 DAA. Para as demais épocas, nenhuma das interações foi significativa; houve influência significativa das coberturas no controle aos 20 e 32 DAA, dos níveis para controle aos 32 DAA e dos herbicidas em todas as avaliações de porcentagem de controle.

Para controle de plantas daninhas, aos 11 DAA, quando aplicado o herbicida diclosulam, não foi constatada diferença significativa entre as coberturas. Para o imazaquin, houve maior porcentagem de controle na palha de capim-pé-de-galinha, diferindo significativamente apenas de sorgo (Tabela 8). Através da análise por contrastes, observou-se na testemunha tratada com diclosulam melhor controle das plantas daninhas que a tratada com imazaquin, não diferindo apenas das coberturas de sorgo e capim-braquiária, também tratadas com este herbicida.

Também aos 11 DAA, não houve diferença significativa entre os níveis de palha que receberam o herbicida diclosulam, porém, quando aplicado o imazaquin, os níveis diferiram entre si, com maior porcentagem de controle no maior nível de palha (dados não mostrados).

O controle das plantas daninhas aos 20 e 32 DAA foi mais eficaz quando os herbicidas foram associados às palhas de sorgo, milheto forrageiro $e$ capim-braquiária (Tabela 9). Por contrastes, aos 20 DAA, foi observada diferença significativa entre as testemunhas, com maior média para a tratada com diclosulam, que não diferiu das palhas de sorgo e capim-pé-de-galinha. Posteriormente, aos 32 DAA, mesmo apresentando, entre as testemunhas, maior porcentagem de controle, a tratada com diclosulam diferiu de todas as coberturas. 
Tabela 8. Percentagem de controle das plantas daninhas, aos 11 dias após a aplicação (DAA), em pré-emergência, dos herbicidas diclosulam e imazaquin sobre quatro tipos de cobertura, além das testemunhas (sem palha). Uberlândia (MG), 2004/2005

\begin{tabular}{lcc}
\hline Tipos de cobertura & Diclosulam & Imazaquin \\
\hline Sorgo & 95,63 a A & 88,50 b B \\
Milheto forrageiro & 94,63 a A & 91,75 ab B \\
Capim-pé-de-galinha & 94,75 a A & 94,13 a A \\
Capim-braquiária & 93,13 a A & 89,75 ab B \\
\hline DMS (na linha) & \multicolumn{2}{c}{2,87} \\
DMS (na coluna) & \multicolumn{2}{c}{5,24} \\
Testemunha sem palha & \multicolumn{2}{c}{0,00} \\
e mantida infestada & \multicolumn{2}{c}{87,00} \\
Testemunha sem palha e & 91,75 \\
tratada com os herbicidas & &
\end{tabular}

Com base no teste de Tukey a 5\% de probabilidade, médias seguidas de letra minúscula, nas colunas, comparam tipos de cobertura dentro de cada herbicida e, letras maiúsculas, nas linhas, comparam herbicidas para cada cobertura.

Tabela 9. Percentagem de controle das plantas daninhas sob quatro tipos de cobertura, aos 20 e 32 dias a aplicação (DAA), em pré-emergência, dos herbicidas diclosulam e imazaquin, além das testemunhas (sem palha). Uberlândia (MG), 2004/2005

\begin{tabular}{lcc}
\hline Tipos de cobertura & $20 \mathrm{DAA}$ & $32 \mathrm{DAA}$ \\
\hline Sorgo & $89,69 \mathrm{ab}$ & $87,13 \mathrm{a}$ \\
Milheto forrageiro & $92,44 \mathrm{a}$ & $88,13 \mathrm{a}$ \\
Capim-pé-de-galinha & $88,69 \mathrm{~b}$ & $84,13 \mathrm{~b}$ \\
Capim-braquiária & $90,19 \mathrm{ab}$ & $87,06 \mathrm{a}$ \\
\hline DMS & 3,74 & 2,14 \\
\hline $\begin{array}{l}\text { Testemunha sem palha e } \\
\text { tratada com diclosulam }\end{array}$ & 87,00 & 74,50 \\
$\begin{array}{l}\text { Testemunha sem palha e } \\
\text { tratada com imazaquin }\end{array}$ & 73,75 & 51,25 \\
$\begin{array}{l}\text { Testemunha sem palha e } \\
\text { mantida infestada }\end{array}$ & 0,00 & 0,00 \\
\hline
\end{tabular}

Médias seguidas pela mesma letra não diferem significativamente entre si pelo teste de Tukey a $5 \%$ de probabilidade.

Aos 32 DAA, constatou-se melhor controle das plantas daninhas no maior nível de palha (dados não mostrados). Por contrastes, verificou-se que todas as testemunhas sem palha diferiram dos níveis de palha e tiveram as menores médias.

Mesmo com o passar do tempo, o herbicida diclosulam foi mais eficaz no controle das plantas daninhas do que o imazaquin, quando aplicado em solo com e sem cobertura (Tabela 10), embora na presença de palha, o controle das plantas daninhas tenha sido potencializado.
Tabela 10. Percentagem de controle das plantas daninhas, aos 20, 32 e 45 dias após a aplicação (DAA), em préemergência, dos herbicidas diclosulam e imazaquin em solo coberto com palha, além das testemunhas (sem palha). Uberlândia (MG), 2004/2005

\begin{tabular}{|c|c|c|c|}
\hline Herbicidas & 20 DAA & $32 \mathrm{DAA}$ & $45 \mathrm{DAA}$ \\
\hline Diclosulam & $92,66 \mathrm{a}$ & 88,81 a & $86,47 \mathrm{a}$ \\
\hline Imazaquin & $87,84 \mathrm{~b}$ & $84,41 \mathrm{~b}$ & $79,00 \mathrm{~b}$ \\
\hline DMS & 2,66 & 1,18 & 1,84 \\
\hline $\begin{array}{l}\text { Testemunha sem } \\
\text { palha e tratada cor }\end{array}$ & $\begin{array}{c}87,00 \\
\text { diclosulam }\end{array}$ & 74,50 & 73,00 \\
\hline $\begin{array}{l}\text { Testemunha sem } \\
\text { palha e tratada cor }\end{array}$ & $\begin{array}{c}73,75 \\
\text { imazaquin }\end{array}$ & 51,25 & 26,25 \\
\hline $\begin{array}{l}\text { Testemunha sem } \\
\text { palha e mantida in }\end{array}$ & $\begin{array}{l}0,00 \\
\text { stada }\end{array}$ & 0,00 & 0,00 \\
\hline
\end{tabular}

Médias seguidas pela mesma letra não diferem significativamente entre si pelo teste de Tukey a $5 \%$ de probabilidade.

As últimas avaliações de porcentagem de controle e acúmulo de massa foram realizadas aos 45 DAA, quando houve o fechamento por completo do dossel das plantas de soja.

Na tabela 11, observa-se que, quando aplicado o diclosulam, associado ao maior nível de palha de milheto forrageiro, houve menor acúmulo de massa de plantas daninhas. Entretanto, as coberturas não diferiram entre si nos seus menores níveis. Quando tratadas com imazaquin, no menor nível, não foi constatada diferença entre as coberturas. No maior nível, verificou-se menor matéria seca de plantas daninhas sobre as palhas de milheto forrageiro e capim-pé-de-galinha.

Através da comparação por contrastes, constatou-se que a matéria seca das plantas daninhas da testemunha sem palha e mantida infestada foi superior a todos os outros tratamentos, para ambos os herbicidas. Quando aplicado o diclosulam, a sua testemunha tratada não diferiu das coberturas, nos dois níveis estudados. Para o imazaquin, a sua testemunha diferiu das coberturas, em ambos os níveis, resultando em maior acúmulo de massa, o qual foi similar ao da testemunha mantida infestada.

Dependendo das características físico-químicas dos herbicidas, a palha terá maior ou menor influência na sua eficácia (RoDRIGUEs, 1993). A solubilidade em água é tida como a principal característica a conferir maior ou menor capacidade de lixiviação do herbicida em direção ao solo no sistema de semeadura direta. Outras características, no entanto, podem exercer esta influência, como pressão de vapor e polaridade. Os herbicidas diclosulam e imazaquin são classificados com média solubilidade em água e praticamente não voláteis (DEUBER, 2003). 
Tabela 11. Acúmulo de matéria seca das plantas daninhas $\left(\mathrm{g} \mathrm{m}^{-2}\right)$, aos 45 dias após a aplicação (DAA), em pré-emergência, dos herbicidas diclosulam e imazaquin sobre quatro tipos de cobertura e dois níveis de palha, além das testemunhas (sem palha). Uberlândia (MG), 2004/2005

\begin{tabular}{|c|c|c|c|c|}
\hline \multirow{3}{*}{ Tipos de cobertura } & \multicolumn{4}{|c|}{ Níveis de palha $\left(\mathrm{t} \mathrm{ha}^{-1}\right)$} \\
\hline & 3,5 & 5,8 & 3,5 & 5,8 \\
\hline & \multicolumn{2}{|c|}{ Diclosulam } & \multicolumn{2}{|c|}{ Imazaquin } \\
\hline Sorgo & 5,22 a $\mathrm{A}$ & $5,37 \mathrm{~b} \mathrm{~A}$ & 11,80 a $\mathrm{A}$ & $20,13 \mathrm{~b} \mathrm{~A}$ \\
\hline Milheto forrageiro & 4,13 a $\mathrm{B}$ & 2,20 a $\mathrm{A}$ & 12,53 a $\mathrm{A}$ & 4,37 a $\mathrm{A}$ \\
\hline Capim-pé-de-galinha & 5,13 a B & $2,60 \mathrm{ab} A$ & 14,28 a A & 7,52 a $\mathrm{A}$ \\
\hline Capim-braquiária & 2,57 a A & $4,51 \mathrm{ab} B$ & 8,85 a A & $20,14 \mathrm{~b} \mathrm{~B}$ \\
\hline DMS (na linha) & \multicolumn{2}{|c|}{1,70} & \multicolumn{2}{|c|}{9,39} \\
\hline DMS (na coluna) & \multicolumn{2}{|c|}{2,86} & \multicolumn{2}{|c|}{11,81} \\
\hline Test. s/ palha trat. c/ herb. $\left({ }^{1}\right)$ & \multicolumn{2}{|c|}{10,73} & \multicolumn{2}{|c|}{78,89} \\
\hline Test. s/ palha $\left({ }^{2}\right)$ & \multicolumn{2}{|c|}{139,78} & \multicolumn{2}{|c|}{139,78} \\
\hline
\end{tabular}

Com base no teste de Tukey a $5 \%$ de probabilidade, médias seguidas de letra minúscula, nas colunas, comparam tipos de cobertura dentro de cada nível de palha e, letras maiúsculas, nas linhas, comparam os dois níveis para cada de cobertura. $\left({ }^{1}\right)$ Testemunha sem palha e tratada com os herbicidas. $\left({ }^{2}\right)$ Testemunha sem palha e mantida infestada.

Em trabalhos realizados em condições do Estado do Paraná, observaram-se resultados similares aos obtidos no presente estudo. O controle das espécies de plantas daninhas Brachiaria plantaginea, Euphorbia heterophylla e Bidens pilosa pelo herbicida imazaquin não foi comprometido pela presença de 7 e $14 \mathrm{t} \mathrm{ha}^{-1}$ de palha de aveia-preta sobre o solo. Ao contrário, a cobertura morta contribuiu para o controle das plantas daninhas, possibilitando, até mesmo, redução da dosagem recomendada de imazaquin (RoDRIGUES et al., 2000). Os herbicidas diclosulam e flumetsulam proporcionaram controle eficaz das espécies Amaranthus sp., Sida sp. e Bidens pilosa, independentemente da presença da palha de aveiapreta na superfície do solo (BuZATti e SANTOS, 1999).

Outros fatores que exercem grande influência na retenção dos herbicidas pela palha são a quantidade e a época das chuvas que ocorrem após a aplicação.

A esse respeito, Rodrigues (1993) constatou que a precipitação pluvial de $9,7 \mathrm{~mm}$ ocorrida no oitavo dia após a aplicação em pré-emergência do herbicida imazaquin, e a de $15 \mathrm{~mm}$ efetuada no nono dia, assim como as irrigações subseqüentes, foram suficientes para remover o herbicida da palha de trigo para o solo, o que resultou no controle altamente satisfatório das espécies Bidens pilosa, Brachiaria plantaginea e tiguera de trigo.

Selim et al. (2003) relataram que, após a aplicação do herbicida atrazine, grande parte do produto foi retido pela palha de cana-de-açúcar depositada sobre o solo. No entanto, em virtude da sua lixiviação pela água da chuva, parte do herbicida atingiu a superfície do solo com o decorrer do tempo. Uma semana após a aplicação, cerca de $22 \%$ do atrazine ainda permanecia na palha, mesmo após precipitação pluvial acumulada de $23 \mathrm{~mm}$. O mesmo ocorreu para os herbicidas pendimethalin e metribuzin. Além disso, a presença da palha foi altamente benéfica para evitar perdas por escorrimento superficial dos herbicidas aplicados.

Neste trabalho, em 2003/2004, duas horas após a aplicação dos herbicidas, ocorreu precipitação de 10 $\mathrm{mm}$. Nos dois dias seguintes foram quantificados mais $3 \mathrm{~mm}$ e $19 \mathrm{~mm}$. Assim, nos primeiros dois dias houve precipitação pluvial acumulada de $32 \mathrm{~mm}$, suficientes para remover os herbicidas dos resíduos vegetais e atingir o solo. No segundo ano, a primeira chuva ocorreu dois dias após a aplicação dos herbicidas, com volume de 7 $\mathrm{mm}$. Entretanto, no terceiro dia foi registrado mais $25 \mathrm{~mm}$, totalizando $32 \mathrm{~mm}$ nos três primeiros dias. Trinta dias após a aplicação dos herbicidas foram registrados 230 $\mathrm{mm}$ de chuva, no primeiro ano, e $210 \mathrm{~mm}$, no segundo.

Como foi relatado, as coberturas não afetaram negativamente o desempenho dos herbicidas diclosulam e imazaquin, pelo contrário, independentemente dos níveis estudados, complementaram de forma expressiva sua eficácia. O tipo de cobertura é um fator de suma importância, visto que em quantidades similares há respostas distintas entre os resíduos vegetais para o controle de plantas daninhas. O que pode ser justificado pela sua constituição química, associada ou não às propriedades alelopáticas, e até mesmo pela geometria do resíduo vegetal, que condicionará uma cobertura mais eficiente do solo. Neste trabalho, as coberturas, associadas aos dois herbicidas, não diferiram entre si, seja com menor ou maior quantidade de palha na superfície do solo, o que foi consolidado no segundo ano do estudo. 


\section{CONCLUSÃO}

1. Os herbicidas diclosulam e imazaquin não tiveram a eficácia afetada pela presença de palha na superfície do solo, independente da quantidade. Associados às coberturas, obteve-se melhor controle.

\section{REFERÊNCIAS}

BUZATTI, W. J. de S.; SANTOS, A. C. Diclosulam (DE-564) aplicado em pré-emergência no solo com diferentes quantidades de palha de aveia na superfície no controle de plantas daninhas em soja. In: CONGRESSO BRASILEIRO DE SOJA, 1999, Londrina. Anais... Londrina: EMBRAPA Soja, 1999. p. 419.

DAO, T. H. Subsurface mobility of metribuzin as affected by crop residue placement and tillage method. Journal of Environmental Quality, Madison, v. 24, n. 6, p. 1193-1198, 1995.

DEUBER, R. Ciência das plantas infestantes. Jaboticabal: FUNEP, 452 p. 2003.

GASTON, L. A.; BOQUET, D. J.; BOSCH, M. A. Fluometuron wash-off from cover crop residues and fate in a loessial soil. Soil Science, Baltimore, v. 166, n. 10, p. 681-690, 2001.
OLIVEIRA, M. F. de; ALVARENGA, R. C.; OLIVEIRA, A. C. de; CRUZ, J. C. Efeito da palha e da mistura atrazine e metolachlor no controle de plantas daninhas na cultura do milho, em sistema de plantio direto. Pesquisa Agropecuária Brasileira, Brasília, v. 36, n. 1, p. 37-41, 2001.

RODRIGUES, B. N. Influência da cobertura morta no comportamento dos herbicidas imazaquin e clomazone. Planta Daninha, Brasília, v. 11, n. 1/2, p. 21-28, 1993.

RODRIGUES, B. N.; LIMA, J.; YADA, I. F. U.; ULBRICH, A. V.; FORNAROLLI, D. A. Influência da cobertura morta na retenção do imazaquin em plantio direto de soja. Planta Daninha, Botucatu, v. 18, n. 2, p. 231-239, 2000.

SELIM, H. M.; ZHOU, L.; ZHU, H. Herbicide retention in soil as affected by sugarcane mulch residue. Journal of Environmental Quality, Madison, v. 32, n. 4, p. 1445-1454, 2003. 